\title{
Endothelial dysfunction is not a predictor of outcome in chronic obstructive pulmonary disease
}

\author{
Andreas Scherr ${ }^{1 \dagger}$, Desiree M. Schumann ${ }^{1 \dagger}$, Meropi Karakioulaki ${ }^{1}$, Léo Franchetti ${ }^{1}$, Werner Strobel ${ }^{1}$, \\ Michael Zellweger ${ }^{2}$, Michael Tamm ${ }^{1}$ and Daiana Stolz ${ }^{1 *}$
}

\begin{abstract}
Background: Local airway inflammation may cause systemic changes which result in endothelial dysfunction. Only a few studies have used reactive hyperemia peripheral arterial tonometry (RH-PAT) in patients with chronic obstructive pulmonary disease (COPD) in order to measure their endothelial dysfunction.

Objective: To determine the efficacy of endothelial dysfunction, measured by RH-PAT, in assessing disease severity and systemic burden in a cohort of COPD patients.

Methods: In this prospective, monocentric study, 157 patients with moderate to very severe COPD (GOLD class IIIV) were examined for endothelial dysfunction using RH-PAT (Itamar medical Ltd., Caesarea, Israel). In a nestedcohort, examination was repeated at exacerbation. The association between reactive hyperemia index (RHI), augmentation index (Al) and disease severity and outcome parameters was analysed.
\end{abstract}

Results: $57 \%$ of the COPD patients had a dysfunctional endothelium and the median (IQR) RHI was 1.42 (1.27-1.53). Exacerbation of COPD was not associated with a significant change in $\mathrm{RHI}(p=0.625)$ or $\mathrm{Al}(p=0.530)$. None of the diagnostic or clinical outcomes of COPD was associated with RHI or arterial stiffness.

Conclusion: Endothelial dysfunction is common in COPD. However, it does not seem to be a predictor neither of disease severity, nor of outcome and does not change during exacerbations of the disease.

Keywords: Arterial stiffness, COPD, Endothelial dysfunction, Flow-mediated dilation, Reactive hyperemia

\section{Background}

Although preventable and treatable, chronic obstructive pulmonary disease (COPD) is one of the leading causes of mortality worldwide [1-3]. It is associated with extrapulmonary comorbid conditions, such as peripheral vascular disease, osteoporosis, skeletal muscle dysfunction, reduced exercise capacity, erectile dysfunction,

\footnotetext{
* Correspondence: daiana.stolz@usb.ch

${ }^{+}$Andreas Scherr and Desiree M. Schumann contributed equally to this work. 'Clinic of Respiratory Medicine and Pulmonary Cell Research, University Hospital of Basel and University of Basel, Petersgraben 4, 4031 Basel, Switzerland

Full list of author information is available at the end of the article
}

chronic depression, lung cancer and diabetes [4, 5]. These conditions are responsible for the poor outcome of advanced COPD and may reflect the systemic manifestation of COPD [6]. Cardiovascular comorbidities contribute to the morbidity and mortality of COPD and can be detected independently of traditional risk factors in about one third of COPD patients, accounting for about $50 \%$ of deaths [7]. That is because a spill-over of local airway inflammatory mediators into the systemic circulation may result in vascular changes leading to endothelial dysfunction [8]. Endothelial dysfunction may additionally be caused due to a decrease in the availability of nitric oxide (NO) and due to inflammatory- 
mediated changes in the structure of the vessel walls, such as the replacement of degraded elastic fibres by collagen, which increases arterial stiffness [8]. Interestingly, endothelial dysfunction is often described as a common feature of COPD and it seems to be positively correlated with the degree of airway obstruction, thus suggesting a mechanistic link between chronic airway obstruction and cardiovascular risk [9-12].

The main method of determining endothelial dysfunction in patients with COPD is by measuring the flowmediated dilation (FMD) of the brachial artery. Reactive hyperemia-peripheral arterial tonometry (RH-PAT) is a more recent, noninvasive method to evaluate endothelial dysfunction and its use, easier and less operatordependent, has been rapidly increasing. RH-PAT measures pulsatile volume changes in response to reactive hyperemia, a transient increase in organ blood flow that is dependent on NO synthesis and occurs after a brief period of ischemia [13-15]. RH-PAT assesses endothelial dysfunction in relation to the presence of multiple cardiovascular and metabolic risk factors [16] and can successfully predict cardiovascular events in a population with an intermediate cardiac risk profile [17]. Moreover, abnormal RH-PAT results are correlated with ischemic heart disease diagnosed using an invasive method [18].

Endothelial function assessed by digital RH-PAT is expressed as the reactive hyperemia index (RHI). The RHI describes the ratio of average amplitude during reactive hyperemia compared with the pre-occlusion baseline period [19]. A lower RHI is associated with higher complexity of coronary atherosclerotic plaque, larger systemic atherosclerotic plaque burden and adverse cardiovascular events [20-23]. Tanaka et al. [24] proposed RHI cutoff values 1.67 and $2.10 \quad(<1.67$ for abnormal and $\geq 1.67$ and $<2.10$ for borderline, $\geq 2.10$ for normal). On the other hand, the augmentation index (AI) is a measurement of arterial stiffness, which is calculated from a pulse waveform analysis of the peripheral arterial tonometry (PAT) signal at baseline and normalized to a heart rate of $75 \mathrm{bpm} \mathrm{[25].} \mathrm{Lower} \mathrm{AI} \mathrm{values} \mathrm{reflect} \mathrm{better}$ arterial elasticity [25].

Minet et al. investigated endothelial dysfunction in patients with COPD using RH-PAT, but their cohort consisted of only 44 patients [26]. Our objective was, therefore, to investigate endothelial dysfunction using RH-PAT in a larger and well-characterised cohort of COPD patients, so that we could determine the importance of endothelial dysfunction in assessing disease severity and systemic burden in COPD.

\section{Methods}

The PREVENT study [27] is an investigator-initiated and -driven study compiled to the Declaration of Helsinki and Good Clinical Practice Guidelines. The study was approved by the responsible ethics committee (EKNZ 306/10) and was registered at www.controlledtrials.com (identifier ISRCTN 45572998). All patients were recruited from in- and out-patients referred for clinical evaluation and lung function tests to the Clinic of Pneumology, University Hospital of Basel and provided written consent before any study assessments were initiated.

The current study included a nested cohort of the PREVENT study $(n=136)$ and 21 COPD patients from a cohort of 365 patients that were admitted for a planned pulmonary workup during a period of 4 months (Fig. 1). The inclusion criteria were as follows: age $\geq 40$ years; smoking history $\geq 10$ pack-years; moderate to very severe COPD (GOLD class II-IV); clinically relevant disease, as defined by a history of exacerbations in the previous 12 months; stable disease (free of exacerbation) for $\geq 4$ weeks prior to the start of the study. GOLD grades are based on $\mathrm{FEV}_{1} \%$ predicted: $\mathrm{I} \geq 80 \% ; 50 \% \leq \mathrm{II}<80 \%$; $30 \% \leq \mathrm{III}<50 \%$; and $\mathrm{IV}<30 \%$. The exclusion criteria were as follows: pulmonary condition other than COPD; rapid lethal disease; severe immunosuppression including manifested AIDS, organ transplantation or neutropenia $\left(<500 \times 10^{9} / \mathrm{L}\right)$, pregnancy or breastfeeding and known allergy or intolerance to the study medicine. In addition, 14 patients were re-evaluated within $48 \mathrm{~h}$ after an acute exacerbation of COPD (AECOPD).

The assessments for each patient included a detailed history, blood sample collection, a physical examination and a measurement of vital signs and lung function. The 6-min walking test (6MWT) [28], the St. George's respiratory questionnaire (SGRQ), and the COPD assessment test (CAT) were additionally required. Specifically, the $6 \mathrm{MWT}$ is a submaximal exercise test that entails measurement of distance walked over a span of $6 \mathrm{~min}$ and assesses the performance ability in a variety of cardiopulmonary diseases [29]. The SGRQ measures the impact of COPD on overall health, daily life and perceived well-being [30]. It scores from 0 to 100, with higher scores indicating more limitations [30]. The CAT is a patient-completed questionnaire, assessing the impact of COPD (cough, sputum, dyspnoea, chest tightness) on health status [31]. It scores from 0 to 40 and higher scores denote a more severe impact of COPD on a patient's life [31].

Information regarding exacerbations were additionally acquired from the patients for the year preceding the baseline measurements and were classified as mild (requiring medical care and increased dose of short-acting $\beta 2$ agonists), moderate (requiring either antibiotics and/ or parenteral corticosteroids) or severe (requiring hospitalization or resulting in death).

Endothelial function was assessed by a trained and certified study nurse at scheduled and unscheduled visits, 


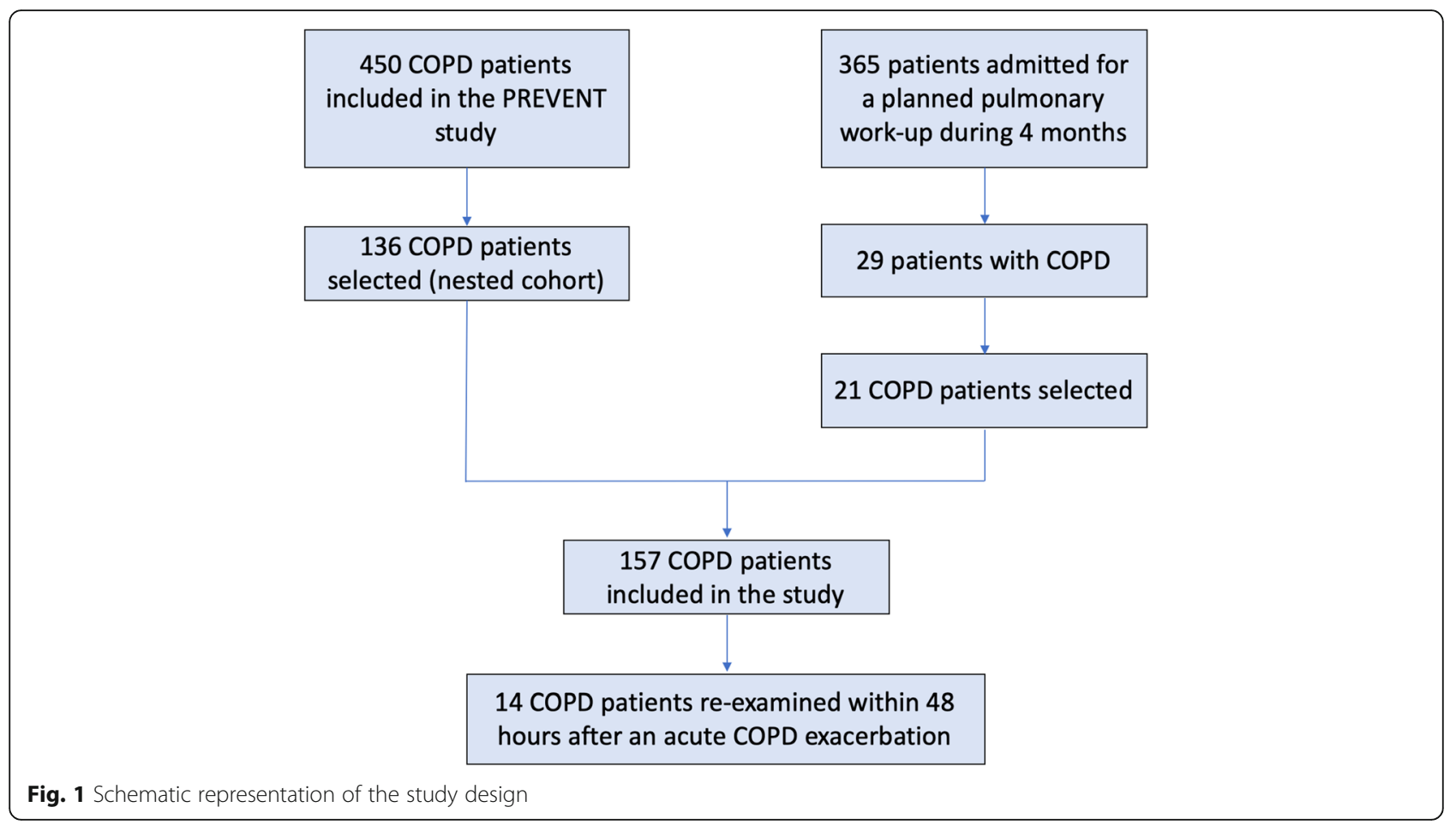

measuring reactive hyperemia with finger plethysmography, according to the recommendations of the manufacturer (Itamar medical Ltd., Caesarea, Israel) [25]. The device also measured AI.

CT-scans were analysed for emphysema and subclassified as centrilobular emphysema and paraseptal emphysema.

For our statistical analysis, the SPSS (Statistical Package for Social Sciences) Release 22.0 software package program (SPPS, Inc., Chicago, IL) was utilized. We based our analysis on the data for FMD obtained by Moro et al. [32]. Correlation of RH-PAT values with other measurable disease-relevant parameters was analysed using the Spearman rho coefficient. A comparison of RH-PAT values during stable disease and AECOPD in the same 14 individuals (paired samples) was performed using Mann-Whitney analysis. The predictive value of RH-PAT for adverse outcome events (AECOPD, hospitalisations, cardiovascular events, death) was analysed by uni- and multivariable cox-regression proportional analysis. Adjustment for confounding variables like age, gender and cardiovascular risk factors was pre-defined according to the literature [26]. All tests were two-tailed and the level of statistical significance was set at 0.05 . Results were expressed as mean (standard deviation) or median (interquartile range), unless otherwise stated.

\section{Results}

In this study, we included 157 patients with stable COPD (Fig. 1), $69 \%$ of which were male and $42 \%$ were smokers (Table 1). The patients were classified as follows: $68 \%$ GOLD II, 22\% GOLD III, and 10\% GOLD IV. The most common cardiovascular comorbidities were arterial hypertension (64\%) and coronary artery disease (28\%). Accordingly, $42 \%$ were on statin medication and $56 \%$ were taking aspirin.

Additionally, $57 \%$ of the COPD patients had a dysfunctional endothelium. The median (IQR) RHI score was $1.42(1.27-1.53)$ and none of the diagnostic or clinical outcomes of COPD was associated with the RHI or arterial stiffness (Table 2). The RHI had no significant effect on time to exacerbation up to 3.3 years after inclusion in the study (Hazard Ratio $=1.001,95 \%$ CI $0.436-$ 2.300, $p=0.998$ ).

Significantly, more male than female and more patients with diabetes as a comorbidity had a dysfunctional endothelium (Table 3). The COPD patients with dysfunctional endothelium had significantly higher BMI than those with normal endothelial function. There were no other differences between the two groups of patients and no association with other cardiovascular comorbidities. Moreover, there was no association between RHI and aspirin (Beta $=-0.052,95 \%$ CI $-0.271-0.140 ; p=$ $0.530)$ nor between endothelial dysfunction and aspirin $(\mathrm{OR}=1.342, p=0.378)$.

There was no significant difference in RHI between patients with emphysema and those without (median 1.6 vs. 1.6, $p=0.89$ ), with centrilobular emphysema or without (median 1.6 vs. $1.7 ; p=0.87$ ) nor with paraseptal emphysema or without (1.6 vs. $1.7 ; \mathrm{p}=0.89)$. Linear 
Table 1 Baseline characteristics of the patients included in the study

\begin{tabular}{|c|c|}
\hline Parameter & $\begin{array}{l}\text { COPD patients }(\boldsymbol{n}=157) \\
\mathrm{n}(\%) ; \text { median }(\mathrm{IQR})\end{array}$ \\
\hline Male & $108(69)$ \\
\hline Age (years) & 67 (59-73) \\
\hline Current smoker & $65(42)^{*}$ \\
\hline Pack years & $53.1(25)$ \\
\hline BMI $\left(\mathrm{kg} / \mathrm{m}^{2}\right)$ & $26(23-31)$ \\
\hline BODE Index & $2(3)$ \\
\hline 6MWT (m) & $420(154)$ \\
\hline Exacerbation rate & $1(0)$ \\
\hline Pulse (bpm) & $74(67-83)$ \\
\hline Systolic blood pressure $(\mathrm{mmHg})$ & $133(121-146)$ \\
\hline Diastolic blood pressure (mmHg) & $74(63-82)$ \\
\hline Unadjusted Charlson Score & $2(2)^{c}$ \\
\hline MMRC score & $2(1)^{a}$ \\
\hline COPD Assessment Score & $16(10)^{b}$ \\
\hline \multicolumn{2}{|l|}{ Lung function } \\
\hline $\mathrm{FEV}_{1}(\mathrm{~L})$ & $1.3(0.9-1.7)^{d}$ \\
\hline FVC (L) & $2.8(2.3-3.4)^{d}$ \\
\hline $\mathrm{FEV}_{1}, \%$ predicted & $52.7(40.1-65.6)^{d}$ \\
\hline FVC, \% predicted & $82.3(71.8-99.6)^{d}$ \\
\hline TLC (L) & $6.7(5.6-7.8)^{\mathrm{e}}$ \\
\hline TLC, \% predicted & $111.0(98.3-129.6)^{\mathrm{e}}$ \\
\hline DLCO_SB (mmol/min/kPa) & $4.5(3.6-5.8)^{\mathrm{a}}$ \\
\hline DLCO_SB, \% predicted & $56.7(46.5-69.8)^{a}$ \\
\hline DLCONA (mmol/min/kPa) & $0.91(0.74-1.16)^{a}$ \\
\hline DLCONA, \% predicted & $66.3(54.3-87.7)^{\mathrm{a}}$ \\
\hline \multicolumn{2}{|l|}{ SGRQ } \\
\hline Symptom score & $42.5(24.7-67.0)$ \\
\hline Activity score & $53.8(41.4-71.0)$ \\
\hline Impact score & $19.5(12.7-36.6)$ \\
\hline Total score & $34.2(23.7-51.5)$ \\
\hline Imaging: CT-scans & $126(80)$ \\
\hline Emphysema & $94(75)$ \\
\hline Centrilobular emphysema & $79(84)$ \\
\hline Paraseptal emphysema & $20(21)$ \\
\hline
\end{tabular}

$B M I$ Body mass index, $B O D E B M I$, aifflow obstruction, dyspnea and exercise capacity, 6MWD 6-min walk distance, MMRC Modified Medical Research Council, FEV 1 Forced expiratory volume in $1 \mathrm{~s}$., FVC Forced vital capacity, TLC Total lung capacity, DLCO Diffusing capacity of the lung for carbon monoxide, SGRQ St. George's Respiratory Questionnaire *2 missing values; ${ }^{\text {a }} 7$ missing values; ${ }^{b} 21$ missing values; ${ }^{c} 22$ missing values; ${ }^{d} 1$ missing value; ${ }^{e} 7$ missing values

regression adjusting for confounding factors such as age, BMI, gender, statin use, diabetes, arterial hypertension, $\mathrm{FEV}_{1}$, smoking status, and pack years, showed no association between emphysema, any type of emphysema and
Table 2 Linear regression looking at the effect of various variables on $\mathrm{RHI}$ values

\begin{tabular}{|c|c|c|c|c|}
\hline & Beta & $95 \%$ Confid & ce Interval & $P-$ \\
\hline & & Lower limit & Upper limit & \\
\hline Age & -0.147 & -0.021 & 0.001 & 0.066 \\
\hline BMI & -0.259 & -0.041 & -0.011 & 0.001 \\
\hline Systolic blood pressure & 0.056 & -0.004 & 0.008 & 0.514 \\
\hline Diastolic blood pressure & -0.008 & -0.010 & 0.009 & 0.923 \\
\hline Heart rate & -0.077 & -0.011 & 0.004 & 0.371 \\
\hline Gender & 0.262 & 0.146 & 0.556 & 0.001 \\
\hline Smoking status & 0.031 & -0.163 & 0.241 & 0.706 \\
\hline $\mathrm{FEV}_{1}(\mathrm{~L})$ & 0.003 & -0.154 & 0.159 & 0.977 \\
\hline BODE index & -0.011 & -0.051 & 0.044 & 0.887 \\
\hline BORG & -0.104 & -0.096 & 0.026 & 0.262 \\
\hline CAT Score & -0.055 & -0.020 & 0.010 & 0.524 \\
\hline $6 \mathrm{MWT}$ & 0.027 & -0.001 & 0.001 & 0.771 \\
\hline
\end{tabular}

$B M I$ Body mass index, $F E V$, Forced expiratory volume in 1 s., BODE BMI, airflow obstruction, dyspnoea and exercise capacity, BORG Borg dyspnoea scale, CAT score COPD assessment score, 6MWD 6-min walk distance

RHI (Table 4). A chi-squared test showed no association between emphysema $(p=0.85)$, centrilobular emphysema $(p=0.94)$, paraseptal emphysema $(p=0.32)$ and the absence or presence of endothelial dysfunction.

Arterial stiffness, as represented by AI, was 10.50 in COPD patients. The factors associated with arterial stiffness were age (Spearman rho $=0.236 ; p=0.001$ ), heart rate (Spearman rho $=-0.406 ; p<0.001$ ) and systolic blood pressure (Spearman $\mathrm{rho}=0.273 ; \mathrm{p}<0.001$ ). The predictors for arterial stiffness in patients with COPD were heart rate (Beta $=-0.409,95 \%$ CI $-0.862--0.408, \mathrm{p}<0.001)$, systolic blood pressure (Beta $=0.346,95 \%$ CI $0.187-0.506 ; \mathrm{p}<$ 0.001), BMI (Beta $=-0.175,95 \%$ CI $-0.944--0.89 ; p=$ 0.018 ) and gender (Beta $=0.264,95 \%$ CI 4.911-16.679; $\mathrm{p}<0.001)$. Arterial stiffness had no effect on time to exacerbation (Hazard ratio $=0.996,95 \%$ CI 0.975-1.017, $p=$ 0.706). Interestingly, there was no significant difference in RHI ( $p=0.625$, Fig. $2 \mathrm{a})$ and AI $(p=0.530$, Fig. $2 \mathrm{~b})$ when we compared patients during a stable phase of COPD and the same patients during an acute exacerbation of COPD.

Arterial stiffness did not change significantly between patients with emphysema compared to those without emphysema (median 11 vs. 10: $p=0.46$ ), with centrilobular emphysema and those without (10 vs. $13 ; p=0.65$ ) and between those with paraseptal emphysema and those without (9 vs. $11 ; p=0.88$ ). A significant association was seen in univariate and multivariate analysis between arterial stiffness and paraseptal emphysema (Table 4).

\section{Discussion}

Up-to-date, this is the largest study evaluating endothelial dysfunction in COPD and the first to evaluate 
Table 3 COPD patients with dysfunctional endothelium compared to COPD patients with normal endothelial function

\begin{tabular}{|c|c|c|c|}
\hline Parameter & $\begin{array}{l}\text { Dysfunctional endothelium, } \boldsymbol{n}=90 \\
\mathrm{n}(\%) ; \text { median (IQR) }\end{array}$ & $\begin{array}{l}\text { Normal endothelial function, } \boldsymbol{n}=67 \\
\mathrm{n}(\%) ; \text { median (IQR) }\end{array}$ & $\boldsymbol{P}$-value \\
\hline Male & $70(65)$ & $38(35)$ & 0.005 \\
\hline Age (years) & $67(61-75)$ & $66(57-72)$ & 0.169 \\
\hline Current smoker & $38(58)$ & $27(42)$ & 0.515 \\
\hline Pack years & $50(40-63)$ & $50(40-70)$ & 0.627 \\
\hline BMI $\left(\mathrm{kg} / \mathrm{m}^{2}\right)$ & $28(25-33)$ & $24(21-27)$ & $<0.001$ \\
\hline 6MWT (m) & $410(315-490)$ & $425(340-480)$ & 0.414 \\
\hline Exacerbation rate in the previous year & $1(0)$ & $1(0)$ & 0.473 \\
\hline Heart rate (bpm) & $75(67-83)$ & $73(67-84)$ & 0.770 \\
\hline Systolic blood pressure (mmHg) & $132(119-145)$ & $133(124-147)$ & 0.422 \\
\hline Diastolic blood pressure (mmHg) & $74(63-82)$ & $72(63-80)$ & 0.295 \\
\hline FeNO (ppm) & $16(11-26)$ & $19(13-25)$ & 0.261 \\
\hline Unadjusted Charlson Score & $2(1-3)$ & $2(1-2)$ & 0.192 \\
\hline CAT Score & $17(11-21)$ & $15(11-21)$ & 0.717 \\
\hline \multicolumn{4}{|l|}{ Lung Function (post-brd) } \\
\hline $\mathrm{FEV}_{1}$, in $\mathrm{L}$ & $1.5(1.2-2.1)$ & $1.4(0.94-1.7)$ & 0.032 \\
\hline$F V C$, in $L$ & $3.0(2.5-3.7)$ & $2.9(2.4-3.4)$ & 0.159 \\
\hline $\mathrm{FEV}_{1}, \%$ predicted & $59.0(44.2-69.6)$ & $55.9(39.0-69.0)$ & 0.469 \\
\hline FVC. \% predicted & $90.1(73.8-102.4)$ & $91.0(76.0-105.2)$ & 0.493 \\
\hline FEV1/FVC \%predicted & $47.5(40.8-60.3)$ & $47.1(34.4-56.1)$ & 0.237 \\
\hline Reactive hyperemia index & $1.42(1.27-1.53)$ & $2.12(1.97-2.48)$ & 0.000 \\
\hline BODE Index & & & 0.872 \\
\hline$\leq 2$ & $48(54)$ & $35(51)$ & \\
\hline$\geq 3$ & $41(46)$ & $33(49)$ & \\
\hline GOLD Grade* & & & 0.862 \\
\hline GOLD ॥ & $61(68.5)$ & $45(66.2)$ & \\
\hline GOLD III & $21(23.6)$ & $15(22.0)$ & \\
\hline GOLD IV & $7(7.9)$ & $8(11.8)$ & \\
\hline mMRC score & & & 0.613 \\
\hline$\leq 2$ & $51(56)$ & $40(44)$ & \\
\hline$\geq 3$ & $36(61)$ & $23(39)$ & \\
\hline \multicolumn{4}{|l|}{ SGRQ } \\
\hline Symptoms score & $47(25-67)$ & $41(23-69)$ & 0.771 \\
\hline Activity score & $54(41-72)$ & $57(37-66)$ & 0.961 \\
\hline Impact score & 19 (13-39) & $20(11-36)$ & 0.610 \\
\hline Total score & $34(25-53)$ & $33(23-49)$ & 0.689 \\
\hline \multicolumn{4}{|l|}{ Comorbidities } \\
\hline Diabetes & $19(86)$ & $3(14)$ & 0.003 \\
\hline Pulmonary arterial hypertension & $6(43)$ & $8(57)$ & 0.274 \\
\hline Renal disease & $11(50)$ & $11(50)$ & 0.495 \\
\hline Arterial hypertension & $61(60)$ & $40(40)$ & 0.208 \\
\hline Congestive heart failure & $12(52)$ & $11(48)$ & 0.609 \\
\hline Coronary artery disease & $29(66)$ & $15(34)$ & 0.146 \\
\hline Cerebrovascular disease & $8(57)$ & $6(43)$ & 0.971 \\
\hline
\end{tabular}


Table 3 COPD patients with dysfunctional endothelium compared to COPD patients with normal endothelial function (Continued)

\begin{tabular}{llll}
\hline Parameter & $\begin{array}{l}\text { Dysfunctional endothelium, } \boldsymbol{n}=90 \\
\mathrm{n}(\%) ; \text { median (IQR) }\end{array}$ & $\begin{array}{l}\text { Normal endothelial function, } \boldsymbol{n}=67 \\
\mathrm{n}(\%) ; \text { median (IQR) }\end{array}$ & $\begin{array}{c}\boldsymbol{P} \text {-value } \\
\text { Myocardial infarction }\end{array}$ \\
$\begin{array}{l}\text { Medication } \\
\text { SHB2AC }\end{array}$ & $7(55)$ & $7(50)$ & 0.870 \\
SABA & $31(65)$ & $17(35)$ & $55(40)$ \\
LABA/ICS & $81(60)$ & $4(25)$ & 0.385 \\
LABA & $12(75)$ & $54(40)$ & 0.470 \\
LAMA & $81(60)$ & $7(41)$ & 0.648 \\
Mucolytics/Antioxidants & $10(59)$ & $23(37)$ & 1.000 \\
Statins & $39(63)$ & $33(40)$ & 0.863 \\
Aspirin & $50(60)$ & $26(36)$ & 0.223 \\
Ace inhibitor & $46(64)$ & 0.377
\end{tabular}

BMI Body mass index, 6MWD 6-min walk distance, CAT score COPD assessment score, brd bronchodilator, FEV, Forced expiratory volume in 1 s., FVC Forced vital capacity, BODE BMI, airflow obstruction, dyspnoea and exercise capacity, GOLD Gold Initiative for Chronic Obstructive Lung Disease, GOLD grades are based on FEV1\% predicted: $50 \% \leq \mathrm{II} \leq 80 \% ; 30 \% \leq \mathrm{III} \leq 50 \%$; and IV $\leq 30 \%$, mMRC Modified Medical Research Council Dyspnoea scale, SGRQ St. George's Respiratory Questionnaire, SHB2AC Short-acting beta 2 agonist plus anticholinergic, SABA Short-acting beta 2 agonist, LABA/ICS Long-acting beta 2 agonist plus glucocorticosteroids, LABA Long acting beta 2 agonist, LAMA Long-acting muscarinic antagonist

potential changes in endothelial dysfunction between stable state and exacerbation of COPD using RH-PAT. We found that $57 \%$ of the patients with COPD had endothelial dysfunction. This is comparable to the results of Minet et al. [26], who indicated endothelial dysfunction in $50 \%$ of their COPD patients. Malerba et al. [33] reported a higher incidence of endothelial dysfunction (75\%) in COPD patients and a lower RHI score (1.31). This might potentially be attributable to the small sample size of their study $(n=16)$.

Similar to the vast majority of COPD patients, our patients had several cardiovascular comorbidities. Indeed, we found an association between endothelial dysfunction and diabetes mellitus. However, we found no association between dysfunctional endothelium and other cardiovascular comorbidities or aspirin, a medication considered to influence endothelial function [34]. This is surprising and could point to a technical fault, yet, the RHI measured for patients with arterial hypertension $(\mathrm{RHI}=$ $1.8 \pm 0.7$ ) was similar to that reported by Weisrock et al. $(\mathrm{RHI}=1.7 \pm 0.4$ to $1.8 \pm 0.4)$ [35]. Additionally, we confirmed the finding of van der Heijden et al. [36] that $\mathrm{BMI}$ is associated with endothelial dysfunction. On the other hand, more than half of the patients assessed in our study had arterial hypertension. Weisrock et al. [35] indicated that PAT is not a reliable method for measuring endothelial dysfunction in patients with arterial hypertension. This could, therefore, explain why we found no association between RHI and most cardiovascular comorbidities or aspirin in our study.

Unlike Marchetti et al. [37], Ozben et al. [38] and Urban et al. [39], in our study endothelial dysfunction was similar at stable state and exacerbation of COPD. This finding is rather intriguing, as exacerbations of COPD are linked to bacterial and viral infections, increase in local and systemic inflammation, hypoxia,

Table 4 Association of emphysema with reactive hyperemia index and arterial stiffness

\begin{tabular}{|c|c|c|c|c|}
\hline & \multicolumn{2}{|l|}{ Univariate analysis } & \multicolumn{2}{|l|}{ Multivariate analysis $^{\mathbf{a}}$} \\
\hline & Beta-estimate \pm SEM & $\boldsymbol{P}$-value & Beta-estimate \pm SEM & $\boldsymbol{P}$-value \\
\hline \multicolumn{5}{|l|}{ RHI } \\
\hline Emphysema & $0.034 \pm 0.13$ & 0.78 & $-0.05 \pm 0.15$ & 0.74 \\
\hline Centrilobular emphysema & $0.08 \pm 0.19$ & 0.70 & $0.10 \pm 0.19$ & 0.60 \\
\hline Paraseptal emphysema & $0.03 \pm 0.06$ & 0.68 & $0.04 \pm 0.06$ & 0.48 \\
\hline \multicolumn{5}{|l|}{ Arterial stiffness } \\
\hline Emphysema & $1.8 \pm 3.8$ & 0.64 & $3.2 \pm 4.3$ & 0.457 \\
\hline Centrilobular emphysema & $0.3 \pm 5.0$ & 0.95 & $-6.4 \pm 5.1$ & 0.210 \\
\hline Paraseptal emphysema & $4.7 \pm 1.6$ & 0.005 & $4.3 \pm 1.5$ & 0.006 \\
\hline
\end{tabular}

${ }^{\mathrm{a}}$ Model adjusted for age, gender, body mass index, smoking status, pack years, $\mathrm{FEV}_{1}$, arterial hypertension, diabetes mellitus, and statin use 


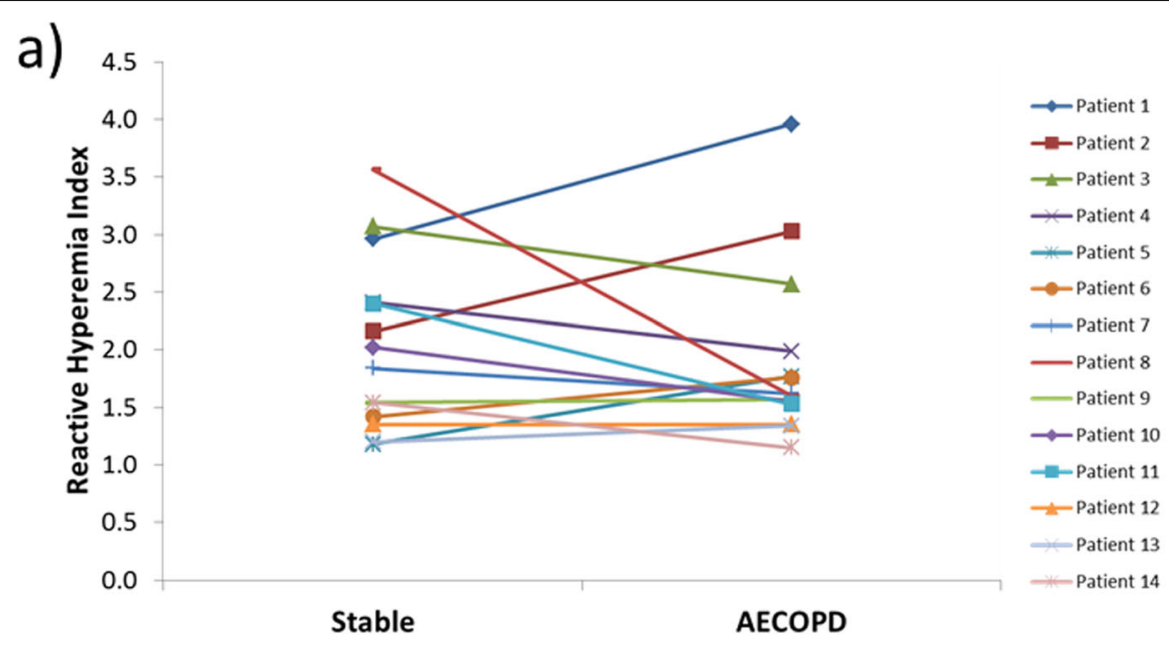

b)

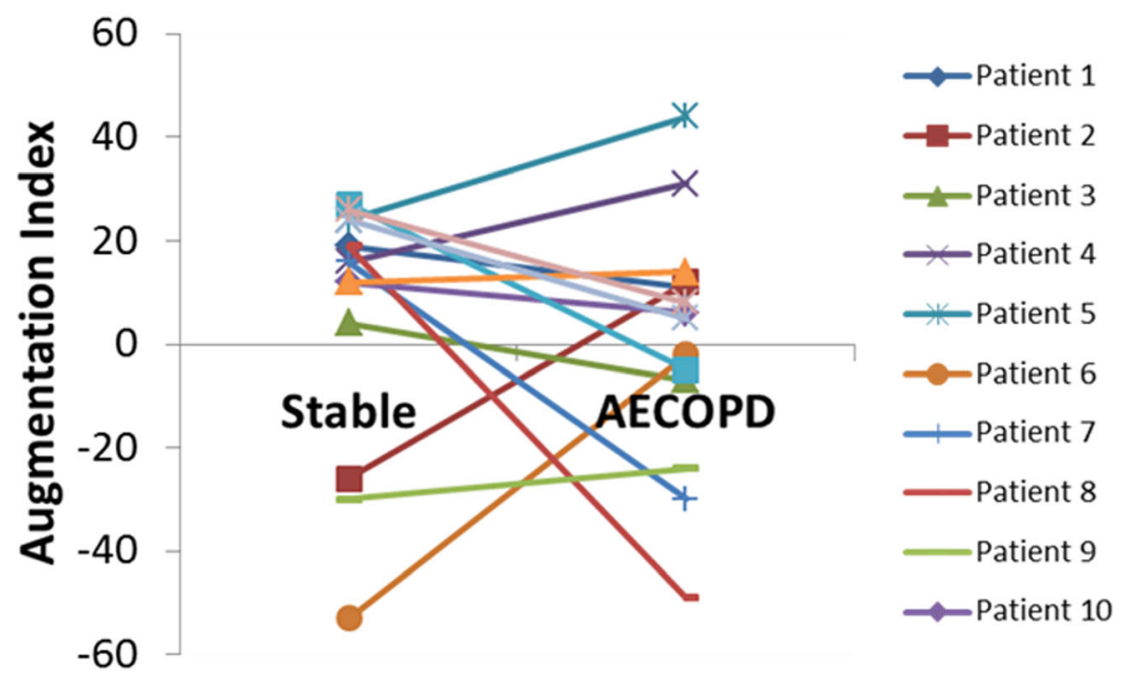

Fig. 2 a Reactive hyperemia index $(\mathrm{RHI})$ and (b) arterial stiffness, as measured by the augmentation index (AI) remained unchanged during stable state and exacerbation, as assessed by the paired t-test ( $p=0.625$ and $p=0.530$ accordingly)

pulmonary arterial hypertension and congestive heart failure; all these conditions are independently related to endothelial dysfunction [40-42]. Furthermore, there is a well-known increase in cardiovascular risk associated with exacerbation of COPD [43,44]. On the other hand, although Marchetti et al. [37] and Ozben et al. [38] found lower FMD during exacerbation compared to the recovery period, they found no difference between patients with COPD in recovery and controls. They also found no difference in brachial artery diameter during exacerbation and recovery and no association between FMD and lung function [10, 37, 38]. That said, considering the small sample size used for the exacerbation analysis, it would be prudent to look at endothelial dysfunction before and after exacerbation in a larger cohort.
In two previous studies, Minet et al. [26] and Malerba et al. [33] found an association between RHI and FEV ${ }_{1}$. However, the current results suggest no association between RHI and any COPD parameter i.e. airflow limitation, exercise capacity, BODE index, GOLD status or modified Medical Research Council (mMRC) dyspnoea scale. These differences could lie in the fact that both previous studies had relatively small populations $(n=44$ and $n=16$, respectively). In addition, the discrepancies in the findings may be attributed to the fact that: 1) our study only excluded COPD patients with other pulmonary conditions, rapid lethal disease and severe immunosuppression and therefore affords a more reasonable representation of the general COPD population, while, on the other hand, Malerba et al. [33] excluded patients with a history of any cardiovascular disease except 
arterial hypertension, diabetes mellitus and if the patient had an exacerbation in the previous 6months; and 2) in the study of Malerba et al. [33], patients had less severe COPD than the patients in our study. In a number of studies, both FMD and RHI are lower in COPD patients than in controls, but the association with COPD parameters is tenuous [45, 46]. Eickhoff et al. [10] found an association between FMD and $\mathrm{FEV}_{1} \%$ predicted in a univariate analysis, but no significant association between FMD and GOLD status. Moro et al. [32] found an association between FMD and airflow limitation $\left(\mathrm{FEV}_{1} /\right.$ $\mathrm{VC}$ ), however, they did not measure or adjust for brachial artery diameter. Barr et al [47] found an association between FMD and $\mathrm{FEV}_{1}$, but this association was present both in COPD and non-COPD patients. Clarenbach et al. [48] demonstrated that a change in FMD was associated with a change in $\mathrm{FEV}_{1}$ in COPD patients after lung volume reduction surgery. However, they did not look at the relationship between FMD and $\mathrm{FEV}_{1}$ at baseline, nor did they take COPD medication into account. Importantly, Barr et al. [47] found that COPD medication is associated with large differences in FMD.

Unlike Bhatt et al. [49], we found no association between RHI or AI and centrilobular emphysema. This could be because coronary calcification, which was used in the analysis by Bhatt et al. [49], is an independent process with different pathways compared to endothelial dysfunction [50]. There was, however, an association between paraseptal emphysema and arterial stiffness. Patients with paraseptal emphysema are at higher risk of developing lung cancer [51]. Arterial stiffness is associated with haematological malignancies [52], but its role in lung cancer is unknown.

Our study has several limitations. It was a monocentric study including patients with COPD receiving extensive treatment for their disease. In addition, we did not exclude patients with cardiovascular comorbidities. Strengths included the full characterisation of the study population, the multivariable adjustment for several confounding factors and the inclusion of a large COPD population with commonly encountered comorbidities, which assures the generalizability of our results.

\section{Conclusions}

In conclusion, we found that $57 \%$ of patients with COPD had an incidence of endothelial dysfunction with a median (IQR) RHI of 1.42 (1.27-1.53). However, RHI was not associated to any COPD-related outcome and endothelial dysfunction was similar at stable state and at exacerbation of COPD. In addition, endothelial dysfunction, as measured using RH-PAT, is neither a predictor of disease severity nor outcome in COPD.

\section{Abbreviations}

6MWT: 6-min walking test; 6MWD: 6-min walking distance; Al: Augmentation index; BMI: Body mass index; COPD: Chronic obstructive pulmonary disease; $\mathrm{FEV}_{1}$ : Forced expiratory volume in $1 \mathrm{~s}$; FMD: Flow-mediated dilation;

RHI: Reactive hyperemia index; RH-PAT: Reactive hyperemia peripheral arterial tonometry

\section{Acknowledgments \\ Not applicable.}

\section{Author contributions}

Data collection, accuracy of data, statistical analysis, writing of the manuscript, contribution to the discussion of results, finalization of the manuscript and approval of the submitted article: AS, DMS, MK, WS, MZ, MT and DS; conception of the research project, contribution in clinical work, integrity and accuracy of data, preparation and approval of the submitted article: DS.

\section{Funding}

This study forms a nested cohort of the PREVENT study, which was primarily funded by a Swiss National Foundation grant to Prof. D. Stolz (PPOOP3_128412/1) and by the Clinic of Pneumology of the University Hospital Basel.

Availability of data and materials

The datasets used and analysed during the current study are available from the corresponding author on reasonable request.

Ethics approval and consent to participate

All patients consent to participate in the study. The study was approved by the ethics committee of the Northwestern and Central Switzerland.

\section{Consent for publication}

All patients signed informed consents for publication of their data in the study.

\section{Competing interests}

The authors declare that they have no competing interests.

\section{Author details}

${ }^{1}$ Clinic of Respiratory Medicine and Pulmonary Cell Research, University Hospital of Basel and University of Basel, Petersgraben 4, 4031 Basel, Switzerland. ${ }^{2}$ Clinic of Cardiology, University Hospital Basel, Petersgraben 4, 4031 Basel, Switzerland.

Received: 24 November 2019 Accepted: 31 March 2020

Published online: 20 April 2020

References

1. World Health Organisation. The top 10 causes of death; 2014. www.who.int/ mediacentre/factsheets/fs310/en/.

2. Organisation WH. Chronic obstructive pulmonary disease; 2016. www.who. int/mediacentre/factsheets/fs315/en:.

3. Mathers $C D$, Loncar D. Projections of global mortality and burden of disease from 2002 to 2030. PLoS Med. 2006:3:11.

4. Sin DD, Man SF. Why are patients with chronic obstructive pulmonary disease at increased risk of cardiovascular diseases? The potential role of systemic inflammation in chronic obstructive pulmonary disease. Circulation. 2003;107(11):1514-9.

5. Celli BR, MacNee W. ATS/ERS task force. Standards for the diagnosis and treatment of patients with COPD: a summary of the ATS/ERS position paper. Eur Respir J. 2004;23(6):932-46.

6. Boschetto P, Beghe B, Fabbri LM, Ceconi C. Link between chronic obstructive pulmonary disease and coronary artery disease: implication for clinical practice. Respirology. 2012;17:422-31.

7. Nussbaumer-Ochsner Y, Rabe KF. Systemic manifestations of COPD. Chest. 2011;139(1):165-73.

8. Seals DR, Tanaka H, Clevenger CM, Monahan KD, Reiling MJ, Hiatt WR, et al. Blood pressure reductions with exercise and sodium restriction in postmenopausal women with elevated systolic pressure: role of arterial stiffness. J Am Coll Cardiol. 2001;38:506-13. 
9. Clarenbach CF, Senn O, Sievi NA, Camen G, van Gestel AJ, Rossi VA, et al. Determinants of endothelial function in patients with COPD. Eur Respir J. 2013;42:1194-204.

10. Eickhoff P, Valipour A, Kiss D, Schreder M, Cekici L, Geyer K, et al. Determinants of systemic vascular function in patients with stable chronic obstructive pulmonary disease. Am J Respir Crit Care Med. 2008;178:1211-8.

11. Maclay JD, McAllister DA, Mills NL, Paterson FP, Ludlam CA, Drost EM, et al. Vascular dysfunction in chronic obstructive pulmonary disease. Am J Respir Crit Care Med. 2009;180:513-20.

12. Mills NL, Miller JJ, Anand A, Robinson SD, Frazer GA, Anderson D, et al. Increased arterial stiffness in patients with chronic obstructive pulmonary disease: a mechanism for increased cardiovascular risk. Thorax. 2008;63:306-11.

13. Bonetti PO, Pumper GM, Higano ST, Holmes DR Jr, Kuvin J, Lerman A. Noninvasive identification of patients with early coronary atherosclerosis by assessment of digital reactive hyperemia. J Am Coll Cardiol. 2004:44(11):2137-41.

14. Kuvin JT, Patel AR, Sliney KA, Pandian NG, Sheffy J, Schnall RP, et al. Assessment of peripheral vascular endothelial function with finger arterial pulse wave amplitude. Am Heart J. 2003;146(1):168-74.

15. Nohria A, Gerhard-Herman M, Creager MA, Hurley S, Mitra D, Ganz P. Role of nitric oxide in the regulation of digital pulse volume amplitude in humans. J Appl Physiol. 2006;101(2):545-8.

16. Hamburg NM, Keyes MJ, Larson MG, Vasan RS, Schnabel R, Pryde MM, et al. Cross-sectional relations of digital vascular function to cardiovascular risk factors in the Framingham heart study. Circulation. 2008;117:2467-74.

17. Korkmaz H, Akbulut M, Ozbay Y, Koc M. A new noninvasive method of evaluating the endothelial function: the measurement of the resistive index after reactive hyperemia of the brachial artery. Echocardiography. 2010;27:873-7.

18. Targonski PV, Bonetti PO, Pumper GM, Higano ST, Holmes DR, Lerman A Coronary endothelial dysfunction is associated with an increased risk of cerebrovascular events. Circulation. 2003;107:2805-9.

19. Bruyndonckx L, Radtke T, Eser P, Vrints CJ, Ramet J, Wilhelm M, et al. Methodological considerations and practical recommendations for the application of peripheral arterial tonometry in children and adolescents. Int J Cardiol. 2013;168(4):3183-90.

20. Maeda H, Sugiyama S, Jinnouchi H, Matsuzawa Y, Fujisue K, Hirata Y, et al. Advanced peripheral microvascular endothelial dysfunction and polyvascular disease in patients with high cardiovascular risk. J Cardiol. 2016; 67(5):455-62.

21. Matsuzawa Y, Li J, Aoki T, Guddeti RR, Kwon TG, Cilluffo R, et al. Predictive value of endothelial function by noninvasive peripheral arterial tonometry for coronary artery disease. Coron Artery Dis. 2015;26(3):231-8.

22. Matsuzawa Y, Sugiyama S, Sumida H, Sugamura K, Nozaki T, Ohba K, et al. Peripheral endothelial function and cardiovascular events in high-risk patients. J Am Heart Assoc. 2013;2(6):e000426.

23. Rubinshtein R, Kuvin J, Soffler M, Lennon RJ, Lavi S, Nelson RE, et al. Assessment of endothelial function by non-invasive peripheral arterial tonometry predicts late cardiovascular adverse events. Eur Heart J. 2010:31(9):1142-8.

24. Tanaka A, Tomiyama H, Maruhashi T, Matsuzawa Y, Miyoshi T, Kabutoya T, et al. Physiological diagnostic criteria for vascular failure. Hypertension. 2018; 72(5):1060-71.

25. Brant LCC, Barreto SM, Passos VMA, Ribeiro ALP. Reproducibility of peripheral arterial tonometry for the assessment of endothelial function in adults. J Hypertens. 2013;31:1984-90.

26. Minet C, Vivodtzev I, Tamisier R, Arbib F, Wuyam B, Timsit J-F, et al. Reduced six-minute walking distance, high fat-free-mass index and hypercapnia are associated with endothelial dysfunction in COPD. Respir Physiol Neurobiol. 2012:183:128-34

27. Stolz D, Hirsch HH, Schilter D, Louis R, Rakic J, Boeck L, et al. Intensified therapy with inhaled corticosteroids and long-acting beta2-agonists at the onset of upper respiratory tract infection to prevent chronic obstructive pulmonary disease exacerbations. A multicenter, randomized, double-blind, placebo-controlled trial. Am J Respir Crit Care Med. 2018;197(9):1136-46.

28. Enright PL, Sherrill DL. Reference equations for the six-minute walk in healthy adults. Am J Respir Crit Care Med. 1998;158:1384-7.

29. Brown AW, Nathan SD. The value and application of the 6-minute-walk test in idiopathic pulmonary fibrosis. Ann Am Thorac Soc. 2018;15(1):3-10.

30. Jones PW, Quirk FH, Baveystock CM, Littlejohns P. A self-complete measure of health status for chronic airflow limitation. The St. George's respiratory questionnaire. Am Rev Respir Dis. 1992;145(6):1321-7.

31. Jones PW, Harding G, Berry P, Wiklund I, Chen WH, Kline LN. Development and first validation of the COPD assessment test. Eur Respir J. 2009;34(3):648-54.
32. Moro L, Pedone C, Scarlata S, Malafarina V, Fimognari F, Antonelli-Incalzi R. Endothelial dysfunction in chronic obstructive pulmonary disease. Angiology. 2008;59(3):357-64.

33. Malerba M, Radaeli A, Nardin M, Clini E, Carpagnano GE, Sciatti E, et al. Endothelial dysfunction assessment by noninvasive peripheral arterial tonometry in patients with chronic obstructive pulmonary disease compared with healthy subjects. Clin Respir J. 2017;12:1-7.

34. Dzeshka MS, Shantsila A, Lip GYH. Effects of aspirin on endothelial function and hypertension. Curr Hypertens Rep. 2016;18:83.

35. Weisrock F, Fritschka M, Beckmann S, Litmeier S, Wagner J, Tahirovic E, et al. Reliability of peripheral arterial tonometry in patients with heart failure, diabetic nephropathy and arterial hypertension. Vasc Med. 2017;22(4):292-300.

36. van der Heijden DJ, van Leeuwen MAH, Janssens GN, Lenzen MJ, van de Ven PM, Eringa EC, et al. Body mass index is associated with microvascular endothelial dysfunction in patients with treated metabolic risk factors and suspected coronary artery disease. J Am Heart Assoc. 2017;6:9.

37. Marchetti N, Ciccolella DE, Jacobs MR, Crookshank A, Gaughan JP, Kashem MA, et al. Hospitalized acute exacerbation of COPD impairs flow and nitroglycerin-mediated peripheral vascular dilation. J Chron Obstruct Pulmon Dis. 2011;8(2):60-5.

38. Oezben B, Eryüksel E, Tanrikulu AM, Papila-Topal N, Celikel T, Basaran Y. Acute exacerbation impairs endothelial function in patients with chronic obstructive pulmonary disease. Arch Turk Soc Cardiol. 2010;38(1):1-7.

39. Urban MH, Valipour A, Kiss D, Eickhoff P, Funk G-C, Burghuber OC. Soluble receptor of advanced glycation end-products and endothelial dysfunction in COPD. Respir Med. 2014;108:891-7.

40. Wedzicha JA, Singh R, Mackay AJ. Acute COPD exacerbations. Clin Chest Med. 2014;35(1):157-63.

41. Rohde G, Wiethege A, Borg I, Kauth M, Bauer T, Gillissen A, et al. Respiratory viruses in exacerbations of chronic obstructive pulmonary disease requiring hospitalisation: a case-control study. Thorax. 2003;58(1):37-42.

42. de Miguel DJ, Chancafe MJ, Jimenez GR. The association between COPD and heart failure risk: a review. Int J Chron Obstruct Pulmon Dis. 2013:8:305-12.

43. Kunisaki KM, Dransfield MT, Anderson JA, Brook RD, Calverley PMA, Celli BR, et al. Exacerbations of chronic obstructive pulmonary disease and cardiac events: a cohort analysis. Am J Respir Crit Care Med. 2018;198(1):51 epub ahead of print.

44. Smith MC, Wrobel JP. Epidemiology and clinical impact of major comorbidities in patients with COPD. Int J Chron Obstruct Pulmon Dis. 2014;27(9):871-88.

45. Vaes AW, Spruit MA, Theunis J, Goswami N, Vanfleteren LE, Franssen FME, et al. Endothelial function in patients with chronic obstructive pulmonary disease: a systematic review of studies using flow mediated dilatation. Expert Rev Respir Med. 2017;11(12):1021-31.

46. Ambrosino P, Lupoli R, lervolino S, De Felice A, Pappone N, Storino A, et al. Clinical assessment of endothelial function in patients with chronic obstructive pulmonary disease: a systematic review with meta-analysis. Intern Emerg Med. 2017;12:877-85.

47. Barr RG, Mesia-Vela S, Austin JHM, Basner RC, Keller BM, Reeves AP, et al. Impaired flow-mediated dilation is associated with low pulmonary function and emphysema in ex-smokers. Am J Respir Crit Care Med. 2007;176:1200-7.

48. Clarenbach CF, Sievi NA, Brock M, Schneiter D, Weder W, Kohler M. Lung volume reduction surgery and improvement of endothelial function and blood pressure in patients with chronic obstructive pulmonary disease - a randomized controlled trial. Am J Respir Crit Care Med. 2015;192(3):307-14.

49. Bhatt SP, Nath HP, Kim Y-I, Ramachandran R, Watts JR, Terry NLJ, et al. Centrilobular emphysema and coronary artery calcification: mediation analysis in the SPIROMICS cohort. Respir Res. 2018;19:257.

50. Han SH, Gerber TC, Suwaidi JA, Eeckhout E, Lennon R, Rubinshtein R, et al Relationship between coronary endothelial function and coronary calcification in early atherosclerosis. Atherosclerosis. 2010;209(1):197-200.

51. Mouronte-Roibas C, Fernandez-Villar A, Ruano-Ravina A, Ramos-Hernandez C, Tilve-Gomez A, Rodriguez-Fernandez P, et al. Influence of the type of emphysema in the relationship between COPD and lung cancer. Int J Chron Obstruct Pulmon Dis. 2018;13:3563-70.

52. Mozos I, Borzak G, Caraba A, Mihaescu R. Arterial stiffness in hematologic malignancies. Onco Targets Ther. 2017;10:1381-8.

\section{Publisher's Note}

Springer Nature remains neutral with regard to jurisdictional claims in published maps and institutional affiliations. 